\title{
APPLICATION OF SEREX-ANALYSIS FOR IDENTIFICATION OF HUMAN COLON CANCER ANTIGENS
}

\author{
O.M. Garifulin ${ }^{1}$ V.O. Kykot ${ }^{2}$, N.Y. Gridina ${ }^{1}$, R.G. Kiyamova ${ }^{1,3 *}$, I.T. Gout ${ }^{4}$, V.V. Filonenko ${ }^{1}$ \\ ${ }^{1}$ Institute of Molecular Biology and Genetics, NAS of Ukraine, Kyiv 03143, Ukraine \\ ${ }^{2}$ National Cancer Institute, Kyiv 03022, Ukraine \\ ${ }^{3}$ Institute of Fundamental Medicine and Biology, Kazan Federal University, Kazan 420008, Russian Federation \\ ${ }^{4}$ Department of Biochemistry and Molecular Biology, Royal Free and University College Medical School, \\ Cower Street, London WC1E 6BT, United Kingdom
}

\begin{abstract}
Background: Colorectal, lung and breast tumors are the most devastating and frequent malignances in clinical oncology. SEREX-analysis of colon cancer leads to identification of more than hundred antigens which are potential tumor markers. With idea that immunoscreening with pool of allogeneic sera is more productive for antigen isolation, SEREX-analysis was applied to four cases of stages II-IV primary colon tumor and 22 new antigens were isolated. Objective: To characterize 22 primary colon cancer antigens isolated by SEREXtechnique. Materials and Methods: Allogenic screening, real-time PCR analysis. Results: After allogeneic immunoscreening, for 5 of $22(22 \%)$ isolated antigens were confirmed colon cancer restricted serological profile solely positive for $14 \%$ of tested colon cancer sera. Through these five antigens, KY-CC-17/ $\beta$-actin has cytoskeleton function; KY-CC-14/ACTR1A and KY-CC-19/TSGA2 participate in chromosome segregation; KY-CC-12/FKBP4 regulates steroid receptor function and KY-CC-15/PLRG1 is a component of spliceosome complex. For the last four antigens tested were found aberrant mRNA expression in some cases of colon tumor. Conclusion: The exploration of identified antigens may define suitable targets for immunotherapy or diagnostic of colon cancer.

Key Words: colon cancer, SEREX-analysis, allogeneic immunoscreening.
\end{abstract}

Colon cancer as frequent case of colorectal tumors along with lung and breast tumors are a significant cause of morbidity and mortality in Western populations associated with a high risk of metastases, recurrence, and early patient death. Colon cancer formation through adenoma to adenocarcinoma and later to its metastatic counterpart involved a multistep cell processes those may associated with aberrant expression of hundreds of genes [1, 2]. It was a long-standing challenge in cancer research if tumor cells proteins may specifically recognized as self-antigens (tumor associated antigens - TAAs) by patient's immune system. Immunologic methods such as T cell epitope cloning [3] and recently emerged as a powerful method for identification of TAAs serological expression cloning (SEREX) [4] applied to different tumors have led to the discovery of a subset of antigens recognized by CTLs and/or by humoral system in tumor-specific manner [5]. TAAs often represent genes with altered normal expression, oncogene i.e. overexpressed or with activity in tumor cells (activated only in neoplastic cells and silence in normal cells, overexpressed in tumor cells, mutated genes), those can predict its possible association with tumorigenesis [6]. Several tumor-specific antigens such as NY-ESO-1, MAGE-1, MAGE-3, SSX2, Melan-A, and tyrosinase proteins are promising sensitive and specific target molecules for cancer screening and diagnosis, cancer immuno-

Submitted: August 05, 2015.

*Correspondence: E-mail: r.g.kiyamova@imbg.org.ua Abbreviations used: SEREX - method of identification of human tumor antigens by serological expression cloning; TAAs - tumorassociated antigens. therapy and development of antigen-specific cancer vaccines [7-9].

In recent years a subset of TAAs reacted exclusively or much higher frequently with sera from colon cancer patients were uncovered by SEREX-analysis of colon primary tumors as well as colon cancer cell lines and colon tumor metastasis [10-12]. As it was showed, a frequency of TAAs for human primary colon tumors is more rare than it was found for its metastases. It is possible that patients with metastasis may have a more augmented IgG response than patients with original tumor [11]. Therefore, SEREX-analysis of primary colon cancer may define new TAAs useful for early tumor diagnosis and immunotherapy intervention. Previously we described of immunogenicity of newly identified colon cancer antigens in sera of patients of different types of tumors [13]. Here we describe identification of these TAAs by SEREX methodology in more detail and characterize in terms of gene identity, tumor-specific immunogenicity and expression in normal colon and colon tumor tissues.

\section{MATERIALS AND METHODS}

Tissue samples. The colon primary tumor samples were obtained from the National Cancer Institute (Kyiv, Ukraine) as surgical specimens, frozen in liquid nitrogen and stored at $-80^{\circ} \mathrm{C}$. The histological classification of tumors was confirmed by histopathological examination at the Department of Pathology, National Cancer Institute (Kyiv, Ukraine). Tumor serum samples were obtained at the same Institute from 20 patients (35-62 years old) including sera samples from 14 coIon cancer patients and 6 gastric cancer patients. Control sera were obtained from 18 individuals with no evidence of malignancy (27-62 years old). All 
sera samples were processed in the same way and stored with $50 \%$ glycerol at $-20{ }^{\circ} \mathrm{C}$. Consent forms were obtained from all patients. The study protocol was approved by the Ethics Committee of the Institute of Molecular Biology and Genetics.

mRNA preparation and construction of $C D N A$ libraries. Normal colon and colon primary tumor samples were obtained as surgical specimens and frozen in liquid nitrogen with following storage at $-80{ }^{\circ} \mathrm{C}$. Total RNA was prepared by the guanidinium thiocyanate method [14], and mRNA was purified by the Dynabeads Oligo(dT) ${ }_{25}$ kit (Dynal, Oslo, Norway). 5 ug of mRNA was used for construction of oligo(dT)-primed double-stranded cDNA ligated into the lambda ZAP II expression vector (Stratagene, La Jolla, CA). A total of four cDNA libraries were constructed with titers of $1-3 \cdot 10^{6}$, and the average inserts size of $1.2-1.5 \mathrm{~kb}$ (Table 1 ).

Table 1. Colon cancer cDNA libraries analyzed by SEREX

\begin{tabular}{|c|c|c|c|c|c|c|}
\hline $\begin{array}{l}\text { cDNA } \\
\text { Library }\end{array}$ & $\begin{array}{c}\text { Colon tumor } \\
\text { (histology; stage) }\end{array}$ & Titer & Serum type & $\begin{array}{l}\text { Clones } \\
\text { scree- } \\
\text { ned }\end{array}$ & $\begin{array}{l}\text { Posi- } \\
\text { tive } \\
\text { clones }\end{array}$ & $\begin{array}{l}\text { Ge- } \\
\text { nes }\end{array}$ \\
\hline $1 \mathrm{C}$ & $\begin{array}{l}\text { Poorly differentiated, } \\
\text { metastases in lymph } \\
\text { nodes; stage IV }\end{array}$ & $2 \times 10^{5}$ & Autologous & $2 \times 10^{5}$ & 5 & 2 \\
\hline $2 \mathrm{C}$ & $\begin{array}{l}\text { Moderately differen- } \\
\text { tiated, lymph node } \\
\text { hyperplasia; stage III }\end{array}$ & $2 \times 10^{6}$ & Autologous & $2.5 \times 10^{5}$ & 3 & 2 \\
\hline $3 C$ & $\begin{array}{l}\text { Moderately differen- } \\
\text { tiated; stage II }\end{array}$ & $1 \times 10^{5}$ & Autologous & $1 \times 10^{5}$ & 1 & 1 \\
\hline $4 C$ & $\begin{array}{l}\text { Moderately differen- } \\
\text { tiated; stage III }\end{array}$ & $0.2 \times 10^{5}$ & $\begin{array}{l}\text { Allogene- } \\
\text { ic (pool } \\
\text { of } 6 \text { sera } \\
\text { from stages } \\
\text { II-IV colon } \\
\text { cancer pa- } \\
\text { tients) }\end{array}$ & $0.2 \times 10^{5}$ & 37 & 17 \\
\hline Total & & & & & 46 & 22 \\
\hline
\end{tabular}

Immunoscreening. Sera used for immunoscreening were stored at $-20{ }^{\circ} \mathrm{C}$ with $50 \%$ glycerol. In order to remove antibodies reactive with the vector system sera prior to immunoscreening were diluted at 1:10 in TBS and absorbed through overnight incubation at $4{ }^{\circ} \mathrm{C}$ with Sepharose 4B (Pharmacia, Uppsala, Sweden) coupled to lysates from $E$. coli XL1 and lambda ZAP II-infected E. coliXL1 synthesized as described previously [15]. Final sera dilutions (1:100) were prepared in TBS with $0.2 \%$ non-fat dried milk (Marwell, England) and $0.01 \% \mathrm{NaN}_{3}$ as preservative. The cDNA libraries were not amplified prior to immunoscreening procedure. Immunoscreening of cDNA libraries was performed as described [10], except recombinant phage plated at concentration of $10^{4} / 15 \mathrm{~cm}$ plate. Allogeneic immunoscreening of positive clones was developed with sera dilution at 1:100 as described [10]. Serum reactivity was detected with the alkaline phosphatase substrate, 4-nitro blue tetrazolium chloride/5-bromo-4-chloro-3-indolylphosphate (Sigma, St. Louis, MO, USA). Serum was considered as reactive when positive staining was observed during immunoscreening.

DNA Sequencing. Monoclonalized phage cDNA clones were converted to pBluescript phagemids by in vivo excision according to user manual (Stratagene, La Jolla, CA, USA). The cDNA inserts were sequenced with universal M13mp18 primer using the DYEnamic ET Terminator Cycle Sequencing Kit (Amersham Biosciences, Buckinghamshire, England) and ABI Prism automated DNA sequencer (Perkin Elmer, Norwalk, CT).

$\boldsymbol{R} \boldsymbol{T}-\boldsymbol{P C R}$ analysis. PCR primers (Invitrogen, Paisley, Scotland) with melting temperature between 60-65 ${ }^{\circ} \mathrm{C}$ were designed to amplify cDNA fragments of 400-500 bp represented adjacent exons of correspondent genes in order to check possible genomic DNA contamination in PCR product bands. The integrity of synthesized cDNAs was determined by the amplification of $\beta$-actin. RT-PCR was performed using HotStarTag DNA polymerase (Qiagen, $\mathrm{GmbH}$, Germany) with 35 cycles of $1 \mathrm{~min}$ at $94^{\circ} \mathrm{C}, 1 \mathrm{~min}$ at $65^{\circ} \mathrm{C}$, and $1 \mathrm{~min}$ at $72^{\circ} \mathrm{C}$, followed by $7 \mathrm{~min}$ at $72{ }^{\circ} \mathrm{C}$. The sequences of primers used for amplification were as follows: $\mathrm{KY}$-CC-8: forward, 5'CAGCGTTATTCTCATTGCCTG; reverse, 5'CTCCACTGACATCTTCCATTG; KY-CC-12: forward, 5'CAGAAGGTCCTGCAGCTCTAC; reverse, 5'GATGGACATATGTTCATGTGC; KY-CC-14: forward, 5'GACAGGCTCCTGAGTGAAGTG; reverse, 5'CCTAGGATGGTCAGCAGCAAG; KY-CC-15: forward, 5'TTATACGGCATTATCATGGAC; reverse, 5'AAGATGCATGGTGCCATTGTC; KY-CC-19: forward, 5'ACGGCCGAGCTCATTCACCTG; reverse, 5'TCTCGGCTCACTTCATCTTAG.

Real-time $\boldsymbol{R T}$-PCR. For real-time RT-PCR were used 6 normal colon cDNAs and 9 colon cancer cDNAs with the same primer pairs combination as described above. Thermal cycling and fluorescent monitoring were performed using an ABI7700 Sequence Analyzer (Applied Biosystems, Foster City, CA, USA). As endogenous control was used $\beta$-actin. Triplicate $P C R$ reactions were prepared for each cDNA sample with SYBR Green I PCR mix (Qiagen, GmbH, Germany). PCR consisted of 40 cycles of $94{ }^{\circ} \mathrm{C}$ denaturation (1 min), $65^{\circ} \mathrm{C}$ annealing ( $\left.1 \mathrm{~min}\right)$, and $72{ }^{\circ} \mathrm{C}$ extension ( $1 \mathrm{~min}$ ) with following denaturation at $65-94{ }^{\circ} \mathrm{C}$ for $20 \mathrm{~min}$ to determine PCR products melting curve. The point at which a PCR product is first detected above a fixed threshold $(\mathrm{Ct})$ was determined for each sample, and the average of triplicate samples was calculated. Respective $\mathrm{Ct}$ values were normalized $(\Delta \mathrm{Ct})$ by subtracting the $\mathrm{Ct}$ value obtained for $\beta$-actin control. For 6 normal colon cDNA samples normalized $\Delta \mathrm{Ct}$ was calculated as the mean value. The relative concentrations of genes-specific mRNAs in colon cancer cDNAs compare to normal colon tissue $(\Delta \Delta \mathrm{Ct})$ were calculated by subtracting the normalized mean $\Delta \mathrm{Ct}$ value obtained for normal colon cDNAs from those obtained with 9 colon tumor samples $(\Delta \Delta \mathrm{Ct}=\Delta \mathrm{Ct}$ of tumor $\Delta \mathrm{Ct}$ of normal colon), and the relative concentration was determined as $2^{-\Delta \Delta \mathrm{ct}}$.

\section{RESULTS}

SEREX defined cDNAs clones. Immunoscreening of the four primary colon cancer cDNA expression libraries with autologous or allogeneic serums produced a total of 48 serum-positive clones. Sequence analysis 
of cDNAs from isolated clones revealed 22 different genes those have been deposited at LICR SEREX database (http://www.licr.org/SEREX.html) under KY-CC1-KY-CC-22 designation. For libraries 1C-3C screened with autologous serums were isolated 9 clones those represent 5 different genes. For library $4 \mathrm{C}$ screened with pool of 6 allogeneic sera obtained from colon cancer (stages II-IV) patients were isolated 37 clones those represent 17 different genes. The largest proportion of antigens has been isolated during allogeneic immunoscreening of library $4 \mathrm{C}$ in contrast to the other free libraries screened with autologous serums (see Table 1). All of isolated antigens, except KY-CC-20 are genes with known function (Table 2). Searching for homology to previously SEREX-defined genes at LICR SEREX database (http://www.licr.org/SEREX.html) revealed that $6(\mathrm{KY}-\mathrm{CC}-2,5,6,15,16,21)$ through 22 antigens isolated at this work have been identified previously in different tumors and only KY-CC-16, 21 found for colon cancer. Despite as much as five libraries have been analyzed, SEREX-defined clones were unique for each immunoscreened library (see Table 2). Analysis of antigen's molecular functions showed that at least 8 antigens are involved in the realisation of the genetic information (KY-CC-1/RPL18, KY-CC-2/se2-2, KY-CC-5/EEF1A1, KY-CC-8/BRCA2, KY-CC-13/RPLP0, KY-CC-15/PLRG1, KY-CC-18/ GNB2L1, KY-CC-22/TRIP11) (see Table 2). The 7 antigens participate in cell proliferation, development and apoptosis (KY-CC-7/PDAP1, KY-CC-8/BRCA2, KYCC-10/TRIM2, KY-CC-11/BTN3A3, KY-CC-18/GNB2L1, KY-CC-19/TSGA2, KY-CC-21/UACA), other 2 (KY-CC-3/ COX1, KY-CC-4/TALDO1) revealed metabolic activity, 6 antigens (KY-CC-9/CXCR4, KY-CC-11/BTN3A3, KYCC-12/FKBP4, KY-CC-16/BRAP, KY-CC-18/GNB2L1, $\mathrm{KY}-\mathrm{CC}-22 / \mathrm{TRIP11})$ are involved in cell signalling and 5 antigens (KY-CC-6/COL1A1, KY-CC-12/FKBP4, KYCC-14/ACTR1A, KY-CC-16/BRAP, KY-CC-17/ACTB) participate in restructuring of the cytoskeleton and cell adhesion (see Table 2). It should be noted that some antigens at least KY-CC-8/BRCA2, KY-CC-11/BTN3A3, KY-CC-12/FKBP4, KY-CC-18/GNB2L1 and KY-CC-22/

Table 2. Characterization of antigens identified by immunoscreening of colon cancer cDNA expression libraries

\begin{tabular}{|c|c|c|}
\hline Antigen & Gene homology & Molecular Function \\
\hline Y-CC-1/RPL18 & Ribosomal protein L18 (RPL18) & NA synthesis. Part of the 60S ribosomal subunit \\
\hline $\mathrm{KY}-\mathrm{CC}-2 / \mathrm{se} 2-2$ & $\begin{array}{l}\text { CEP290 gene, Aliase CTCL tu- } \\
\text { mor antigen se } 2-2\end{array}$ & $\begin{array}{l}\text { Part of the tectonic-like complex which is required for tissue- } \\
\text { ciliary membrane composition. Activates ATF4-mediated tran }\end{array}$ \\
\hline KY-CC-3/COX1 & $\begin{array}{l}\text { Cytochrome c oxidase subunit } \\
\text { I (COX1) }\end{array}$ & $\begin{array}{l}\text { Cytochrome } \mathrm{c} \text { oxidase is the component of the respiratory chain that catalyzes the reduction of oxy- } \\
\text { gen to water }\end{array}$ \\
\hline KY-CC-4/TALD01 & Transaldolase 1 (TALD01) & $\begin{array}{l}\text { nzyme of the pentose phosphate pathway and important for the balance of metabolites } \\
\text { ntose-phosphate pathway }\end{array}$ \\
\hline KY-CC-5/EEF1A1 & $\begin{array}{l}\text { Translation elongation factor } \\
1 \text { alpha } 1 \text { (EEF1A1) }\end{array}$ & $\begin{array}{l}\text { Promotes the GTP-dependent binding of aminoacyl-tRNA to the A-site of ribosomes during protein } \\
\text { biosynthesis }\end{array}$ \\
\hline KY-CC-6/COL1A1 & 1) type I, alpha 1 & n type I, alpha 1, play role in fibril forming, putative downregulated c-Myc target gene \\
\hline KY-CC-7/PDAP1 & $\begin{array}{l}\text { associated protein } \\
\text { P1) }\end{array}$ & GFB \\
\hline KY-CC-8/BRCA2 & 2 region, mRNA se- & NA repair through homo \\
\hline KY-CC-9/CXCR4 & kine (C-X-C motif), re- & ts as a receptor for extra \\
\hline KY-CC-10/TRIM2 & motif-containing & ind \\
\hline KY-CC-11/BTN3A3 & $\begin{array}{l}\text { Butyrophilin, subfamily 3, mem- } \\
\text { ber A3 (BTN3A3) }\end{array}$ & $\begin{array}{l}\text { Plays a role in T-cell responses in the adaptive immune response. Als } \\
\text { play role in cell proliferation and development }\end{array}$ \\
\hline BP4 & $\begin{array}{l}\text { FK506 binding protein } 4 \text { (59kD) } \\
\text { (FKBP4) }\end{array}$ & $\begin{array}{l}\text { Immunophilin protein with PPlase and co-chaperone activities. Component of sterc } \\
\text { heterocomplexes through interaction with heat-shock protein } 90 \text { (HSP90). Acts als }\end{array}$ \\
\hline KY-CC-13/RPLP0 & Ribosomal protein, large, & $(60 S)$ is the functional equivalent of $E$. coli protein $\mathrm{L} 10$ \\
\hline
\end{tabular}
PO (RPLPO)

KY-CC-14/ACTR1A ARP1 actin-related protein 1 homolog $A$, centractin alpha (yeast) (ACTR1A)

KY-CC-15/PLRG1 Pleiotropic regulator 1 (PRL1 homolog) (PLRG1)

KY-CC-16/BRAP BRCA1 associated protein (BRAP)

KY-CC-17/ACTB Actin, beta (ACTB)

KY-CC-18/GNB2L1 Guanine nucleotide binding protein (G protein), beta polypeptide 2-like 1 (GNB2L1)

KY-CC-19/TSGA2 H. sapience testes specific

KY-CC-20/IMA2 homolog (mouse) (TSGA2) AGE:4893383 KY-CC-21/UACA EST: IMAGE: 4893383

Component of a multi-subunit complex involved in microtubule based vesicle motility. It is associated with the centrosome

Component of the PRP19-CDC5L complex that forms an integral part of the spliceosome and is required for activating pre-mRNA splicing

Negatively regulates MAP kinase activation by limiting the formation of Raf/MEK complexes probably by inactivation of the KSR1 scaffold protein. May also act as a cytoplasmic retention protein with a role in regulating nuclear transport

Actins are highly conserved proteins that are involved in various types of cell motility and are ubiquitously expressed in all eukaryotic cells

Involved in the recruitment, assembly and/or regulation of a variety of signaling molecules and plays a role in many cellular processes. It is a part of the $40 \mathrm{~S}$ ribosomal subunit

May play an important role in male meiosis (By similarity). It is necessary for proper building of the axonemal central pair and radial spokes

No data available for molecular function

Regulates APAF1 expression and plays an important role in the regulation of stress-induced apoptosis. Promotes apoptosis by regulating three pathways, apoptosome up-regulation, LGALS3/galectin-3 down-regulation and NF-kappa-B inactivation peats (UACA)

KY-CC-22/TRIP11 TRIP11 H. sapiens thyroid hor- Binds the ligand binding domain of the thyroid receptor (THRB) in the presence of triiodothyronine mone receptor interactor 11 
TRIP11exhibit multiple functions and were classified in different categories.

Allogeneic immunoscreening of SEREX-defined antigens. In order to determine colon cancer related serological profile of identified antigens allogeneic immunoscreening have been performed with sera obtained from 14 colon cancer and 6 gastric tract cancer patients, as well as 18 healthy donors. Eight of 22 tested antigens reacted with both normal and cancer sera samples; two antigens were positive only for normal sera; seven antigens showed no reaction with any sera and five antigens solely positive only for colon cancer sera (Table 3). For some antigens reacted with cancer and normal sera previously showed their association with autoimmune, inflammatory-related or non-cancerous (viral) diseases (see Table 3). In addition, KY-CC-1/RPL18, KY-CC-8/CG016, KY-CC-18/GNB2L1 and KY-CC-22/ FLJ20542 may represent novel tumor-independent occurring autoantigens firstly isolated in this work. KY-CC-21/UACA, KY-CC-18/GNB2L1 and KY-CC-6/ COL1A1 autoantigens revealed the highest percentage reactivity with both normal and cancer serums tested, ranging from $29 \%$ to $100 \%$ (see Table 3). Five antigens with colon-cancer specific serological profile, namely KY-CC-12/FKBP4, KY-CC-14/ACTR1A, KY-CC-15/ PLRG1, KY-CC-19/TSGA2, KY-CC-17/ $\beta$-actin were reacting totally for $14 \%$ of tested colon cancer sera samples (Table 4). Through these antigens only KY-CC-15/ PLRG1 was previously identified by SEREX-analysis in hepatocellular carcinoma (data unpublished), for the others have not been documented their reactivity with any tumor patients sera.

Table 3. SEREX-defined antigens with not colon cancer related serological profile

\begin{tabular}{|c|c|c|c|c|}
\hline \multirow{2}{*}{ Antigen } & \multicolumn{3}{|c|}{$\begin{array}{c}\text { Serum reactivity (number } \\
\text { of positive sera/number } \\
\text { of sera analysed) }\end{array}$} & \multirow{2}{*}{$\begin{array}{l}\text { Association with } \\
\text { autoimmune } \\
\text { disease } 2 / \text { refe- } \\
\text { rence }\end{array}$} \\
\hline & $\begin{array}{l}\text { Colon } \\
\text { tumor }^{1}\end{array}$ & $\begin{array}{l}\text { Gastrict } \\
\text { tract tu- } \\
\text { mor }\end{array}$ & $\begin{array}{l}\text { Healthy } \\
\text { donors }\end{array}$ & \\
\hline KY-CC-1/RPL18 & $1 / 14$ & $0 / 6$ & $1 / 18$ & No data \\
\hline KY-CC-2/se2-2 & $0 / 14$ & $2 / 6$ & $1 / 18$ & No data \\
\hline $\mathrm{KY}-\mathrm{CC}-3 / \mathrm{COX} 1$ & $0 / 14$ & $0 / 6$ & $0 / 18$ & HT [16] \\
\hline KY-CC-4/TALD01 & $0 / 14$ & $0 / 6$ & $0 / 18$ & MS [17] \\
\hline KY-CC-5/EEF1A1 & $2 / 14$ & $0 / 6$ & $3 / 18$ & No data \\
\hline KY-CC-6/COL1A1 & $12 / 12$ & NT & $11 / 11$ & PBC [18], AP [19] \\
\hline KY-CC-7/PDAP1 & $0 / 14$ & $0 / 6$ & $0 / 18$ & No data \\
\hline KY-CC-8/CG016 & $1 / 14$ & $0 / 6$ & $1 / 18$ & No data \\
\hline KY-CC-9/CXCR4 & $0 / 14$ & $0 / 6$ & $0 / 18$ & No data \\
\hline KY-CC-10/TRIM2 & $0 / 14$ & $0 / 6$ & $0 / 18$ & No data \\
\hline KY-CC-11/BTN3A3 & $0 / 14$ & $0 / 6$ & $0 / 18$ & MS [20] \\
\hline KY-CC-13/RPLP0 & $0 / 14$ & $0 / 6$ & $1 / 18$ & SLE [21] \\
\hline KY-CC-16/BRAP & $0 / 14$ & $0 / 6$ & $0 / 18$ & No data \\
\hline KY-CC-18/GNB2L1 & $5 / 9$ & NT & $9 / 11$ & No data \\
\hline KY-CC-20/IMAGE:4893383 & $1 / 7$ & NT & $2 / 11$ & No data \\
\hline KY-CC-21/UACA & $5 / 14$ & $1 / 6$ & $5 / 18$ & Panuveitis [22] \\
\hline KY-CC-22/FLJ20542 & $1 / 14$ & $0 / 6$ & $2 / 18$ & No data \\
\hline
\end{tabular}

Note: ${ }^{1}$ Data of serum reactivity not include reactivity with autologous or pool of allogeneic sera used for initial SEREX-analysis. ${ }^{2}$ Abbreviations: PBC - primary biliary cirrhosis; AP - adult periodontitis; MS - multiple sclerosis; SLE systemic lupus erythematosus; HT - Hashimoto's thyroiditis.

mRNA expression profile of serologically defined colon cancer specific antigens. KY-CC-12/ FKBP4, KY-CC-14/ACTR1A, KY-CC-15/PLRG1 and KY-CC-19/TSGA2 defined by allogeneic immunoscreening as colon cancer specific antigens were tested RT-PCR and real-time RT-PCR for 6 normal colon cDNAs and 9 colon cancer cDNAs.

Antigens tested by RT-PCR were positive for all coIon cancer CDNAs; KY-CC-15/PLRG1 and KY-CC-19/ TSGA2 were positive for all 6 normal colon cDNAs, therefore KY-CC-12/FKBP4 and KY-CC-14/ACTR1A were positive only for 4 normal colon cDNAs and very weak bands observed for these genes for the other 2 normal colon cDNAs (data not shown). The relationship between tested antigens mRNA expression levels and serological reactivity was not examined for respective colon cancer patients due to their sera were not available for typing.

According to the result of real-time RT-PCR, KYCC-14/ACTR1A mRNA showed increased expression level at 2.5-7.7 times for 8 through 9 tested colon cancer cDNAs compare to normal colon (Figure, a). So, KYCC-14/ACTR1A may have slightly upregulated mRNA expression level as mean at 3.5 times in colon tumors.

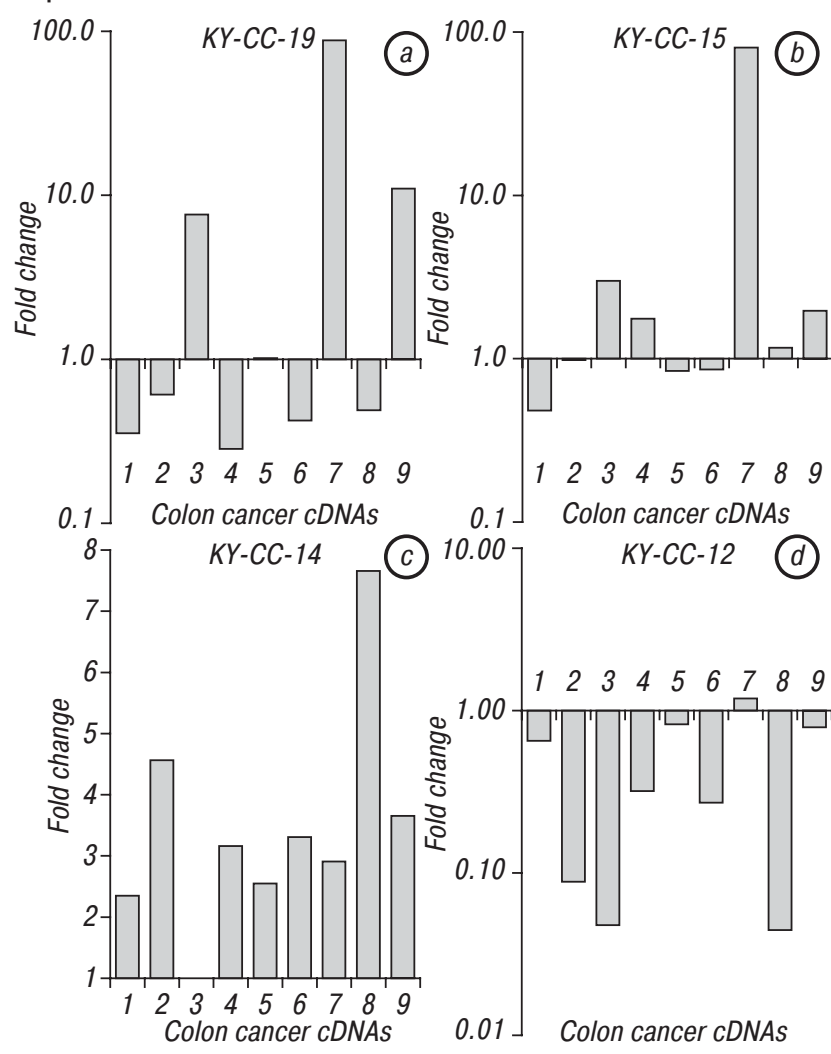

Figure. Real-time RT-PCR results for relative expression level of identified colon cancer related antigens in 9 tested colon cancer cDNA samples. Expression level of antigens in normal colon referred as 1 in all cases

KY-CC-15/PLRG1 and KY-CC-19/TSGA2 showed heterogeneous mRNA expression profile in colon tumor samples with exceptionally high levels of transcripts compare to normal colon associated with the colon cancer case N7 ( 80 and 88 times elevation, correspondently) (Figure, $b, c$ ). KY-CC-19/TSGA2 mRNA expression also increased at 7 times in tumor case $\mathrm{N} 3$ and at 10 times in tumor case $\mathrm{N} 9$, despite for colon cancer cases NN 1, 2, 4, 5, 8 its normal expression down regulated at 2-3.5 times (Figure, b). KY-CC-15/PLRG1 mRNA in addition to tumor case N7 have slightly increased expression at 3 times in tumor case N3 and near the same level of expression compare to normal colon in tumor 
cases NN 1, 2, 4, 5, 6, 8, 9 (difference range at 0.48-1.96) (Figure, c). KY-CC-15/PLRG1 and KY-CC-19/TSGA2 represent the genes with selective activation of normal expression in some cases of colon cancer and may be immunogenic as aberrantly expressed.

By real-time RT-PCR result KY-CC-12/FKBP4 mRNA normal expression down regulated at 11-25 times in tumor cases NN 2, 3, 8 and at 3.1 and 3.7 times in tumor cases NN 4, 6, respectively (Figure, $d$ ). In the others four cases of tested tumors, KY-CC-12/FKBP4 mRNA expression was near at the same range (difference at 0.7-1.2 times) as in normal colon. KY-CC-12/ FKBP4 showed a great down regulation of normal expression in approximately of $1 \frac{1}{3}$ of colon cancer cases.

\section{DISCUSSION}

Utilization of SEREX-analysis led to identification of a broad spectrum normal and tumor sera IgG reactive proteins currently consisted of over 2000 enters at LICR SEREX database (http://www.licr.org/SEREX.html). Exploration of these proteins in term of tumor-specific immunity discovered a subset of antigens as attractive targets for cancer diagnosis and immunotherapy.

It have been previously showed that primary colon tumors analyzed by SEREX methodology may display a small number antigens detected by autologous sera $[10,12]$, despite metastasis counterpart more productive for serum reactive clones [10]. Recently, application of SEREX-analysis to colon cancer cell lines and testis CDNA expression libraries immunoscreened with colon cancer patients allogeneic sera led to identification of about ten new antigens with colon tumor restricted serological profile. It is also has been found a decline in quantity of serum reactive antigens for colon tumor stages II-III patients sera [11, 13]. With idea that serum samples from tumor patients may differ by cancer-related IgG response and tumor consists a mix of different cells, not one cell line, we used for serological screening of one primary colon tumor cDNA expression library pool of 6 allogeneic sera along with autologous serum immunoscreening of the others three synthesized tumor cDNA libraries [13]. Here we describe antigens isolated in more detail.

Of isolated 22 different antigens the largest proportion (17 antigens) were derived from the cDNA expression library screened with pool of allogeneic sera. In contrast, only 5 antigens were obtained from the cDNA expression libraries screened with autologous sera (see Table 1). SEREX-defined antigens were unique for each cDNA library analyzed, i.e. no similar antigens have been found (see Table 2). For 16 of 22 SEREX-defined antigens there are no data about their immunogenecity in any type of cancer according to SEREX database data (http://www.licr.org/SEREX.html). So, it is possible that complete list of serum IgG reactive antigens for colon cancer should be far from completion and many other antigens can be isolated using for immunoscreening a pool of allogeneic sera those increases a chance to recognize a more primary colon tumor antigens. Antigens identified were characterized according their molecular functions and it was shown that the most of them are involved in the implementation of the genetic information including replication, transcription, translation and reparation (see Table 2).

Analysis of frequency of the allogeneic sera antibody response of healthy donors and colon cancer as well as gastric tract tumors patients to the 22 identified antigens showed that 5 (22\%) antigens, namely KYCC-12/FKBP4, KY-CC-14/ACTR1A, KY-CC-15/PLRG1, KY-CC-17/ $\beta$-actin, KY-CC-19/TSGA2 have colon cancer-restricted serological profile. Except KY-CC-15/ PLRG1, previously identified by SEREX in hepatocellular carcinoma (data unpublished), the others four antigens are firstly isolated at this work and all solely positive for $14 \%$ of tested colon cancer allogeneic sera (Table 4). During allogeneic immunoscreening some antigens showed no reactivity with any type of sera tested (see Table 3). We suggest that using a more extended set of normal and cancer serum samples as well as modernization of conditions for large-scale allogeneic immunoscreening should be this problem solving.

Table 4. SEREX-defined antigens with colon cancer related serological profile

\begin{tabular}{|c|c|c|c|c|c|}
\hline \multirow{3}{*}{ Antigen } & \multicolumn{4}{|c|}{$\begin{array}{l}\text { Serum reactivity (number of positive } \\
\text { sera/number of sera analysed) }\end{array}$} & \multirow{3}{*}{$\begin{array}{l}\text { Previously } \\
\text { isolated } \\
\text { by SEREX in }{ }^{2}\end{array}$} \\
\hline & \multicolumn{2}{|c|}{ Colon tumor ${ }^{1}$} & \multirow{2}{*}{$\begin{array}{l}\text { Gastrict } \\
\text { tract tu- } \\
\text { mor }\end{array}$} & \multirow{2}{*}{$\begin{array}{l}\text { Healthy } \\
\text { donors }\end{array}$} & \\
\hline & Total & $\begin{array}{c}\text { Reactive } \\
\text { serum }\end{array}$ & & & \\
\hline KY-CC-12/FKBP4 & $1 / 14$ & 9 & $0 / 6$ & $0 / 18$ & No data \\
\hline KY-CC-14/ACTR1A & $1 / 14$ & 9 & $0 / 6$ & $0 / 18$ & No data \\
\hline KY-CC-15/PLRG1 & $1 / 14$ & 8 & $0 / 6$ & $0 / 18$ & $\begin{array}{l}\text { Hepatocellular } \\
\text { carcinoma }\end{array}$ \\
\hline KY-CC-17/ß-actin & $1 / 14$ & 8 & $0 / 6$ & $0 / 18$ & No data \\
\hline KY-CC-19/TSGA2 & $1 / 14$ & 9 & $0 / 6$ & $0 / 18$ & No data \\
\hline
\end{tabular}

Note: ${ }^{1}$ Data of serum reactivity not include reactivity with autologous or pool of allogeneic sera used for initial SEREX-analysis. ${ }^{2}$ Data obtained at LICR SEREX database.

We were surprised for housekeeping cytoskeletal protein $\beta$-actin identified as colon cancer antigen. Previously have been reported that some patients with type 1 autoimmune hepatitis have anti-actin antibody [23] and $\beta$-actin also a candidate autoantigen in autoimmune inner ear disease [24]. Therefore, recently was showed that the cause for the antiactin immune response in medullary breast cancer (MCB) relates to the actin exposure on the surface of apoptotic MCB cells, allow this intracellular antigen to be exposed to the local humoral immune system [25]. We suggest that apoptosis or intensive necrosis of colon cancer cells may also provoke of humoral immune response to $\beta$-actin. As it was showed for the other housekeeping gene - ATP6S1, putative accessory unit of the vacuolar $\mathrm{H}+$-ATPase complex, despite the broad tissue expression it may stimulate humoral responses in a significant proportion of melanoma and non-small cell lung carcinoma patients treated by vaccination with irradiated autologous tumor cells without provoking clinical autoimmunity [26]. So, study of $\beta$-actin immunogenecity and autoimmunity in different tumours patients may define it is usefulness for detection of apoptotic positive colon cancer variants or cancer treatment. 
As it has been recorded previously, immunogenecity of SEREX-defined antigens may depend on mutation and/or overexpression of correspondent genes in tumor cells those also can be contributed to tumor formation [6, 27]. Sequenced cDNAs for colon cancerspecific serum reactive clones have no any mutations according to comparison with relative matches in GenBank data. Real-time RT-PCR for KY-CC-12/ FKBP4, KY-CC-14/ACTR1A, KY-CC-15/PLRG1, KYCC-19/TSGA2 revealed aberrant distribution its $m R N A$ normal level in some tested colon cancer tissues that can made them implications in tumor etiologic and immunogenecity context.

KY-CC-12/FKBP4 (FKBP52) belongs to a distinct group of structurally related immunophilins and participates in association with $\mathrm{Hsp} 90$ to form chaperoned mammalian steroid receptor complexes into a conformation that is optimal for binding hormone [28-30]. FKBP4 is expressed at varying levels in all human tissues as well as cultured cells tested and its expression is reduced in fibroblastic CCL39 mutant-transformed cells or cells able to grow in low serum-containing medium, suggesting that FKBP4 might participate in the negative feedback control to cell proliferation [31]. Also we found the reduction of FKBP4 mRNA expression in colon tumor comparing to normal colon tissue (Figure, $d$ ). Due to one molecule of FKBP4 have stoichiometry in steroid receptor heterocomplexes with two molecules of hsp90 determined for glucocorticoid receptor [30, 32], progesterone receptor [33], and estrogen receptor [34] misbalance in this ratio due to decreasing in FKBP4 expression possible for colon cancer as well as increasing in heat shock proteins expression reported for gastrointestinal tumors [35] may lead to appearance of nonfunctional steroid receptor. In case of ER- $\beta$ those can mediated protective effects of estrogen replacement therapy and its protein expression is markedly and specifically reduced in colon cancers compared to adjacent normal colon in vivo [36], process described above may be alternative way to inactivation of ER- $\beta$ in ER- $\beta$ positive colon cancer cells as more early event in molecular etiologic of this tumor. Down regulation of FKBP4 expression in colon cancer cells can disrupt normal protein processing for which multiple isoforms have been found [28], as well as concentration in cell to form complex with hsp90 with following generation of aberrant set of peptides presenting by MHC. Recently the same mechanism was proposed for down-regulated genes found by SEREX-analysis as immunogeneic antigens [11].

KY-CC-14/ACTR1A (actin-related protein 1 homolog $A$, centractin alpha (yeast)) is an actin-related protein, and is approximately $60 \%$ identical at the amino acid level to conventional actin. It comprises the most abundant $42.6 \mathrm{kD}$ subunit in the dynactin complex involved in a diverse array of cellular functions, including ER-to-Golgi transport, the centripetal movement of lysosomes and endosomes, spindle formation, chromosome movement, nuclear positioning, and axonogenesis [37]. We found for approximately half of tested colon tumors increasing of ACTR1A mRNA expression at 3-8 times compare to normal tissue (Figure, $c$ ), those can predict immunogenecity of correspondent protein. Recently have been found that dynactin complex may participate in maintaining of multicentric chromosomes during chromosome segregation in tumor cells [38]. So, ACTR1A may associated as one of many components for survival of cancer cells with multiple chromosome aberration. The next study of dynactin complex in tumor cells may define appropriated targets for therapy oriented on disruption of control mechanism aberrant chromosome segregation.

KY-CC-19/TSGA2 represents protein, also known as RSPH1, is present in the sperm flagellum [39]. This protein is a homolog for mouse testes specific A2 protein and has unknown function in the humans [40]. Mouse TsgA2, initially believed to be confined to the testis in male mice [41, 42]. TsgA2 have been isolated using testis-specific polyclonal antibodies from an expression cDNA library prepared from the mouse testis [41]. Immunohistochemical examination revealed TsgA2 specific association with the metaphase chromosomes and spindles suggesting that the protein plays important roles in male meiosis [41]. We found that KY-CC-19/TSGA2 mRNA expression in human not restricted only to reproductive tissues because it was found in testis, normal colon and colon tumors. In two through 9 colon tumors tested TSGA2 mRNA expression was elevated at about 10 times and for the other one at near 90 times compare to normal colon (Figure, a). Such overexpression of TSGA2 in some cases of colon tumors may be a reason for its immunogenecity. According to postulated for TsgA2 important role in metaphase chromosomes segregation it is also possible, as in case of ACTR1A, that multiple chromosome aberration in tumor cells require some specific modification in molecular machinery acted in cell division and human TSGA2 one of that for tumorgenesis process.

KY-CC-15/PLRG1 represents human homolog to pleiotropic regulator 1 found in Arabidopsis [43]. The human proteins CDC5L (hCDC5) and PLRG1 are both highly conserved components of a multiprotein complex that is a subunit of the spliceosome and interaction between them is essential for pre-mRNA splicing progression $[44,45]$. It has been shown that overexpression of CDC5L in mammalian cells shortened the G2 phase of the cell cycle and a dominant negative mutant of the protein lacking the activation domain slowed G2 progression and delayed entry into mitosis [46] and also PLRG1 deficiency causes an earlier cell cycle arrest, as cells cannot progress through S phase [45]. We found that in one case of coIon tumor mRNA expression of KY-CC-15/PLRG1 was elevated at 80 times compare to normal colon those can be as reason for IgG antibody response in case of tumors with shortened G2 phase, i.e. with rapidly growth characteristic.

In conclusion, we found that using pool of allogeneic sera obtained from colon cancer patients for SEREX-analysis of colon primary cancer may 
be an optimal way to overcome a difficulty with isolation of low number immunoreactive antigens for this tumor. We suggest that best way to complete SEREX characterization of all possible colon cancer antigens is using different stage colon tumors for serum immunoscreening each with pools of sera obtained also for different stage tumors. It was found that primary colon tumors have new unique antigens in comparison to previously isolated, because majority of the last have been obtained for colon cancer cell lines. We confirmed for five through 22 antigens isolated at this work its colon-cancer restricted serological profile requests its next exploration to define suitable targets for colon tumor therapy or diagnostic.

\section{ACKNOWLEDGMENTS}

We thank Dr. U. Sahin and Dr. O. Tureci at III. Medizinische Klinik and Poliklinik, Johannes Gutenberg Universitat Mainz, Germany, for introduction to us allogeneic SEREX-analysis procedure and help in RT-PCR analysis of cDNAs. This study was supported by Russian Science Foundation (project 15-15-20032).

\section{REFERENCES}

1. Velculescu VE, Zhang L, Vogelstein B, et al. Serial analysis of gene expression. Science 1995; 270: 484-7.

2. Lin YM, Furukawa Y, Tsunoda T, et al. Molecular diagnosis of colorectal tumors by expression profiles of 50 genes expressed differentially in adenomas and carcinomas. Oncogene 2002; 21: 4120-8.

3. van der Bruggen $\mathbf{P}$, Traversari $\mathbf{C}$, Chomez P, et al. Agene encoding an antigen recognized by cytolytic $\mathrm{T}$ lymphocytes on a human melanoma. Science 1991; 254: 1643-7.

4. Sahin U, Tureci O, Schmitt H, et al. Human neoplasms elicit multiple specific immune responses in the autologous host. Proc Natl Acad Sci USA 1995; 92: 11810-3.

5. Stockert E, Jager E, Chen YT, et al. A survey of the humoral immune response of cancer patients to a panel of human tumor antigens. Exp Med 1998; 187: 1349-54.

6. Scanlan MJ, Gordon CM, Williamson B, et al. Identification of cancer/testis genes by database mining and mRNA expression analysis. Int J Cancer 2002; 98: 485-92.

7. Stockert E, Jager E, Chen YT, et al. A survey of the humoral immune response of cancer patients to a panel of human tumor antigens. J Exp Med 1998; 187: 1349-54.

8. Giesen E, Jilaveanu LB, Parisi F, et al. NY-ESO-1 as a potential immunotherapeutic target in renal cell carcinoma. Oncotarget 2014; 5: 5209-17.

9. Kumara S, Grieco MJ, Caballero OL, et al. MAGEA3 is highly expressed in a subset of colorectal cancer patients. Cancer Immunity 2012; 12: 16-25.

10. Scanlan MJ, Chen YT, Williamson B, et al. Characterization of human colon cancer antigens recognized by autologous antibodies. Int J Cancer 1998; 76: 652-8.

11. Scanlan MJ, Welt S, Gordon CM, et al. Cancer-related serological recognition of human colon cancer: identification of potential diagnostic and immunotherapeutic targets. Cancer Res 2002; 62: 4041-7.

12. Hongda C, Simone W, Sha T, et al. Blood autoantibodies against tumor-associated antigens as biomarkers in early detection of colorectal cancer. Cancer Letters 2014; 346: 178-87.

13. Kiyamova R, Garifulin O, Gryshkova V, et al. Preliminary study of thyroid and colon cancers-associated antigens and their cognate autoantibodies as potential cancer biomarkers. Biomarkers 2012; 4: 362-71.
14. Chomczynski P, Sacchi N. Single-step method of RNA isolation by acid guanidinium thiocyanate-phenol-chloroform extraction. Anal Biochem 1987; 162: 156-9.

15. de Wet JR, Fukushima H, Dewji NN, et al. Chromogenic immunodetection of human serum albumin and alphaL-fucosidase clones in a human hepatoma cDNA expression library. DNA 1984; 3: 437-47.

16. Libert F, Ruel J, Ludgate M, et al. Thyroperoxidase, an auto-antigen with a mosaic structure made of nuclear and mitochondrial gene modules. EMBO J 1987; 6: 4193-6.

17. Banki K, Colombo E, Sia F, et al. Oligodendrocytespecific expression and autoantigenicity of transaldolase in multiple sclerosis. J Exp Med 1994; 180: 1649-63.

18. Tishler M, Alosachie I, Barka N, et al. Primary Sjogren's syndrome and primary biliary cirrhosis: differences and similarities in the autoantibody profile. Clin Exp Rheumatol 1995; 13: 497-500.

19. Anusaksathien O, Singh G, Matthews N, et al. Autoimmunity to collagen in adult periodontal disease: immunoglobulin classes in sera and tissue. J Periodontal Res 1992; 27: 55-61.

20. Winer S, Astsaturov I, Cheung RK, et al. T cells of multiple sclerosis patients target a common environmental peptide that causes encephalitis in mice. J Immunol 2001; 166: 4751-6.

21. Zampieri S, Degen W, Ghiradello A, et al. Dephosphorylation of autoantigenic ribosomal $\mathrm{P}$ proteins during Fas-L induced apoptosis: a possible trigger for the development of the autoimmune response in patients with systemic lupus erythematosus. Ann Rheum Dis 2001; 60: 72-6.

22. Yamada K, Senju S, Nakatsura T, et al. Identification of a novel autoantigen UACA in patients with panuveitis. Biochem Biophys Res Commun 2001; 280: 1169-76.

23. Czaja AJ, Cassani F, Cataleta M, et al. Frequency and significance of antibodies to actin in type 1 autoimmune hepatitis. Hepatology 1996; 24: 1068-73.

24. Boulassel MR, Tomasi JP, Deggouj N, et al. Identification of beta-actin as a candidate autoantigen in autoimmune inner ear disease. Clin Otolaryngol 2000; 25: 535-41.

25. Hansen MH, Nielsen H, Ditzel HJ. The tumorinfiltrating B cell response in medullary breast cancer is oligoclonal and directed against the autoantigen actin exposed on the surface of apoptotic cancer cells. Proc Natl Acad Sci USA 2001; 98: 12659-64.

26. Hodi FS, Schmollinger JC, Soiffer RJ, et al. ATP6S1 elicits potent humoral responses associated with immune-mediated tumor destruction. Proc Natl Acad Sci USA 2002; 99: 6919-24.

27. Chen YT, Gure AO, Tsang S, et al. Identification of multiple cancer/testis antigens by allogeneic antibody screening of a melanoma cell line library. Proc Natl Acad Sci USA 1998; 95: 6919-23.

28. Peattie DA, Harding MW, Fleming MA, et al. Expression and characterization of human FKBP52, an immunophilin that associates with the $90 \mathrm{kDa}$ heat shock protein and is a component of steroid receptor complexes. Proc Natl Acad Sci USA 1992; 89: 10974-8.

29. Ramos P, Guy N, Cox M. Identification and characterization of a putative FKBP52 regulatory surface on the androgen receptor hormone binding domain (567.9). FASEB J 2014; 28: 576-85.

30. Erlejman AG, Lagadari M, Toneatto J, et al. Regulatory role of the 90-kDa-heat-shock protein (Hsp90) and associated factors on gene expression. BBA 2014; 1839: 71-87.

31. Doucet-Brutin S, Renoir M, Le Gallic L, et al. Growthregulated expression of FKBP-59 immunophilin in normal and transformed fibroblastic cells. Exp Cell Res 1995; 220: 152-60. 
32. Rexin M, Busch W, Gehring U. Protein components of the nonactivated glucocorticoid receptor. J Biol Chem 1991; 266: $24601-5$.

33. Rehberger P, Rexin M, Gehring U. Heterotetrameric structure of the human progesterone receptor. Proc Natl Acad Sci USA 1992; 89: 8001-5.

34. Segnitz B, Gehring U. Subunit structure of the nonactivated human estrogen receptor. Proc Natl Acad Sci USA 1995; 92: 2179-83.

35. Ehrenfried JA, Herron BE, Townsend CM Jr, et al. Heat shock proteins are differentially expressed in human gastrointestinal cancers. Surg Oncol 1995; 4: 197-203.

36. Campbell-Thompson M, Lynch IJ, Bhardwaj B. Expression of estrogen receptor (ER) subtypes and ERß isoforms in colon cancer. Cancer Research 2001; 61: 632-40.

37. Lees-Miller JP, Helfman DM, Schroer TA. A vertebrate actin-related protein is a component of a multisubunit complex involved in microtubule-based vesicle motility. Nature 1992; 359: 244-6.

38. Faulkner NE, Vig B, Echeverri CJ, et al. Localization of motor-related proteins and associated complexes to active, but not inactive, centromeres. Hum Mol Genet 1998; 7: 671-7.

39. Ramdas S, Cheng L, Puri P, et al. The Flagellar protein RSPH1 is a candidate regulator of the testis and sperm-restricted protein phosphatase, PP1gamma 2. Biol Reprod 2009; 81: 450.
40. Taketo MM, Araki Y, Matsunaga A, et al. Mapping of eight testis-specific genes to mouse chromosomes. Genomics 1997; 46: 138-42.

41. Tsuchida J, Nishina Y, Wakabayashi N, et al. Molecular cloning and characterization of meichroacidin (male meiotic metaphase chromosome-associated acidic protein). Dev Biol 1998; 197: 67-76.

42. Ling H, Jing L, Yibing H, et al. The mouse T complex gene Tsga2, encoding polypeptides located in the sperm tail and anterior acrosome, maps to a locus associated with sperm motility and sperm-egg interaction abnormalities. Biol Reprod 2006; 74: 633-43.

43. Nemeth K, Salchert K, Putnoky P, et al. Pleiotropic control of glucose and hormone responses by PRL1, a nuclear WD protein, in Arabidopsis. Genes Dev 1998; 12: 3059-73.

44. Ajuh P, Sleeman J, Chusainow J, et al. A direct interaction between the carboxyl-terminal region of CDC5L and the WD40 domain of PLRG1 is essential for pre-mRNA splicing. J Biol Chem 2001; 276: 42370-81.

45. Karamyshevaa Z, Díaz-Martínezb LA, Warringtonc R, et al. Graded requirement for the spliceosome in cell cycle progression. Cell Cycle 2015; 14: 12.

46. Bernstein HS, Coughlin SR. Pombe Cdc5-related protein. A putative human transcription factor implicated in mitogen-activated signaling. J Biol Chem 1997; 272: 5833-7. 